\title{
Sistematização e distribuição da inervação lombar e sacral em Arctocephalus australis
}

Tiane Ferreira de CASTRO ${ }^{1}$ Daniel Alexandre Stüpp de SOUZA ${ }^{2}$

Rodolfo Pinho da SILVA FILHO $^{3}$

Malcon Andrei Martinez PEREIRA ${ }^{4}$

\section{Correspondência para:}

Malcon Andrei Martinez Pereira malconantato@yahoo.com.br Rua Sarmento Leite, 500 II Andar Laboratório 12 Neurobiologia Comparada, Porto Alegre-RS, 90050-170

Recebido para publicação: 22/11/2005 Aprovado para publicação: 29/08/2007

\author{
1 - Acadêmico de Medicina Veterinária da Universidade Federal de Pelotas, \\ Pelotas-RS \\ 2 - Acadêmico de Ciências Biológicas da Universidade Federal de Pelotas, \\ Pelotas-RS \\ 3 - Centro de Recuperação de Animais Marinhos da Fundação Universidade \\ Federal de Rio Grande, RS \\ 4 - Laboratório Neurobiologia Comparada, Departamento Fisiologia do \\ Instituto Ciências Básicas Saúde da Universidade Federal Rio Grande do Sul, \\ Porto Alegre-RS
}

\section{Resumo}

Objetivando descrever a inervação originada a partir dos ramos ventrais lombares e sacrais, fez-se um estudo, mediante a dissecação de dois exemplares de lobos-marinhos (Arctocephalus australis), oriundos do CRAM-FURG, onde chegaram em óbito. As estruturas nervosas constituintes dos plexos lombar e sacral possuem origem dos ramos ventrais dos nervos espinhais que formam-se dos segmentos medulares $\mathrm{L}_{1}$ a $\mathrm{S}_{3}$. Assim, pode-se observar que, os formados dos segmentos $\mathrm{L}_{1}$ a $\mathrm{L}_{3}$ são unissegmentares, sendo respectivamente os nervos Ílio-hipogástrico e Ílio-inguinal e Cutâneo Femoral Lateral. Da união dos segmentos $\mathrm{L}_{3}-\mathrm{L}_{4}$ surgem os nervos Genito-femoral, Obturatório e Femoral. Da confluência dos segmentos $\mathrm{L}_{4-5}-\mathrm{S}_{1}$ formase um tronco nervoso, o plexo isquiático, que emite os nervos: Glúteos Cranial e Caudal, Cutâneo Femoral Caudal e Isquiático. O nervo Isquiático ramifica-se em Cutâneos Surais Lateral e Caudal, Tibial, Fibular Comum. O nervo Pudendo (divide-se nos nervos dorsal do pênis ou clitóris e perineais superficial e profundo) e Retal Caudal têm origem dos segmentos $\mathrm{S}_{2-3}$. Com base nestes dados podemos inferir que a inervação lombar e sacral têm origem similar a outras espécies de mamíferos, contudo sua organização e distribuição refletem as modificações adaptativas aos hábitos destes animais, principalmente a locomoção em meio aquático.

\section{Introdução}

O Arctocephalus australis (Mammalia, Carnivora, Otariidae) é uma espécie de lobomarinho sul-americano que habita desde o sul do Peru, Chile, Argentina, Ilhas Malvinas, Uruguai e sul do Brasil. Freqüentemente registrado nos meses de inverno e primavera nos estados costeiros do sul e sudeste do Brasil. O registro mais setentrional assinalado na costa brasileira seria Itaúna. ${ }^{1}$

No começo do século, caçadores ávidos pelo couro e óleo abundantes do animal desembarcavam próximos das enormes colônias de reprodução, ao longo da costa da Patagônia, e os matavam. ${ }^{2}$ Tal fato implicou na sua existência, atualmente, em pequeno número e, portanto são protegidos nas regiões em que habitam, embora as populações da costa do Atlântico tenham mostrado sinais de recuperação. Isto se reflete na dificuldade de obtenção de mais espécimes para fins de estudo, justificando o baixo número de exemplares utilizados nesta pesquisa. Não há registros de colônias de reprodução no Brasil, mas devido as corrente das Malvinas, chegam com freqüência nos meses de inverno às praias 
do Rio Grande do Sul. ${ }^{1}$ Apesar dos lobosmarinhos serem facilmente vítimas de derramamentos de óleo, o principal impacto que sofrem em águas brasileiras é a interação com a pesca, na qual os animais são agredidos diretamente por pescadores ou capturados acidentalmente. ${ }^{3}$ Tais fatores geralmente implicam em lesões que comumente acometem os membros torácico e pélvico, por serem a forma de locomoção, ataque e defesa desta espécie.

Em algumas destas situações, profissionais voltados à recuperação destes animais conseguem encontrá-los ainda com vida, porém nem sempre tem êxito na reabilitação ou simplesmente em proporcionarem um tratamento apropriado. Deste modo, não podem ser reintroduzidos ao seu meio natural, pois se tornariam presas fáceis, sendo destinados a viver em cativeiros nos centros de reabilitações. Isto decorre do fato de desconhecerem a anatomia e as características próprias desenvolvidas com o intuito de melhor interar-se com o meio onde vive. Em virtude de tais fatores propomos a realização de um trabalho que objetiva descrever a inervação lombar e sacral em lobo-marinho sul-americano (Arctocephalus australis), visto que esta se encontra intimamente relacionada à locomoção, interação com o meio e reprodução deste animal.

A terminologia utilizada em nossa pesquisa teve como base a Nomina Anatômica Veterinária ${ }^{4}$ e para os termos não inclusos nesta, por serem particulares desta categoria de mamíferos marinhos, utilizouse citações de Miller ${ }^{5}$ e Howell ${ }^{6}$, os quais adotou-se como referência para determinar a nomenclatura apropriada para osteologia e, ainda, para os músculos presentes nos territórios nervosos.

\section{Material e Método}

Neste trabalho procedeu-se o estudo de dois exemplares de lobos-marinhos (Arctocephalus australis), um macho e uma fêmea, os quais foram estudados mediante dissecação macroscópica. Os animais eram oriundos do Centro de Recuperação de Animais Marinhos - FURG (CRAMFURG), e foram encontrados em óbito pelos profissionais desta instituição. Nesta, realizaram o procedimento de necropsia dos espécimes, promovendo a evisceração dos órgãos das cavidades torácica e abdominal. De posse dos exemplares procedeu-se a remoção do tegumento comum e tecido subcutâneo através de uma incisão dorsalmente ao nível da última vértebra torácica. Em seguida iniciou-se a remoção da musculatura adjacente às estruturas nervosas visadas em nossa pesquisa. Durante o processo de identificação de cada nervo, utilizaram-se compressas de ácido acético glacial $3 \%$, objetivando uma melhor evidenciação destas estruturas, visto que este procedimento dilata as bainhas que envolvem o tecido nervoso. Durante a dissecação foram analisados dados como origem aparente, território nervoso, trajeto de cada nervo, assim como suas relações com estruturas adjacentes.

\section{Resultados e Discussão}

A inervação lombar e sacral possui origem dos ramos ventrais dos nervos espinhais que formam-se do primeiro segmento medular lombar até o terceiro sacral. Apresentando-se, assim, constituída de modo semelhante a cães ${ }^{7}$ e gatos ${ }^{8}$. Entanto, o número de segmentos constituintes em Arctocephalus australis somam oito, enquanto que em cães e gatos dez. Assim como o descrito para estas espécies, observou-se a existência de nervos unissegmentares e plurissegmentares (Figura 1).

Deste modo observou-se que os segmentos $\mathrm{L}_{1}$ a $\mathrm{L}_{3}$ constituem nervos unissegmentares, onde emerge do primeiro segmento lombar o nervo Ílio-hipogástrico, que apresenta uma situação subperitonial entre as extremidades dos dois primeiros processos transversos lombares (Figura 1). Este se constitui de ramo único, diferente do descrito para carnívoros domésticos, que por apresentarem sete vértebras lombares, possuem os denominados Ílio-hipogástrico 


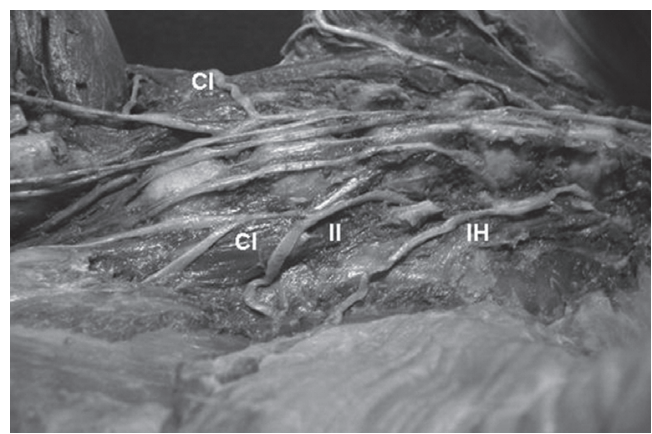

Figura 1 - Fotografia evidenciando a emergência dos nervos unissegmentares ílio-hipogástrico (IH $\left.-L_{1}\right)$, Ílio-inguinal $\left(I I-L_{2}\right)$ e Cutâneo Femoral Lateral $\left(\mathrm{Cl}-\mathrm{L}_{3}\right)$

Cranial e Ílio-hipogástrico Caudal, emergindo de $\mathrm{L}_{1}$ e $\mathrm{L}_{2}$, respectivamente. ${ }^{7,8,9}$ Divide-se em ramos que inervam os músculos transverso, oblíquo interno e reto abdominais e posteriormente distribui-se suprindo a pele do escroto, do prepúcio e da glândula mamária. Cursa um trajeto descendente através da região abdominal látero-ventral juntamente ao nervo Ílioinguinal, originado de $\mathrm{L}_{2}$ (Figura 1), que atua concomitante na inervação das mesmas estruturas.

Proveniente do segmento $\mathrm{L}_{3}$ nota-se o nervo Cutâneo Femoral Lateral (Figura 1) que percorre entre os músculos psoas maior e menor, flexores da coluna lombar e articulação coxal. Sua formação é semelhante à relatada em macacos Cebus apella ${ }^{10}$, porém em gatos, $\mathrm{Ghoshal}^{8}$ o descreve sendo constituído pelos ramos ventrais de $\mathrm{L}_{4}-\mathrm{L}_{5}$. Este dirigi-se caudalmente à região ilíaca transpondo a musculatura abdominal, entre os músculos oblíquo externo do abdome e ilíaco. Posteriormente cursa dorsolateralmente à região femoral, onde supre a pele lateral e, distalmente, o músculo tensor da fáscia femoral ${ }^{7}$, encontrando-se sobre a musculatura desta região juntamente ao tecido subcutâneo.

Nas dissecações, constatou-se que os nervos de $\mathrm{L}_{3}-\mathrm{S}_{1}$ constituem o plexo lombossacral (PLS), que se encarrega, primordialmente, de inervar o membro pélvico. Contudo, em carnívoros domésticos, é descrito como sendo formado a partir dos últimos três ou quatro nervos lombares e os dois primeiros sacrais, totalizando de cinco a seis segmentos contínuos. ${ }^{711}$ Atribui-se tal fato a diferença no número de vértebras lombares, que para carnívoros domésticos são sete ${ }^{8,11}$ e nos presentes exemplares cinco, justificando a participação de apenas quatro segmentos na formação deste plexo. Ressalta-se que macacos Cebus apella apresentam o PLS, frequentemente, formado por $\mathrm{L}_{3}-\mathrm{L}_{4}-\mathrm{L}_{5}$, podendo variar de dois a quatro segmentos quando tal formação provém $\mathrm{L}_{3}-\mathrm{L}_{4}$ e $\mathrm{L}_{2}-\mathrm{L}_{5}$, respectivamente, sendo o limite cranial de maior ocorrência $\mathrm{L}_{3}{ }^{10}$, assim como o encontrado em nosso trabalho. Em cervos do pantanal ${ }^{12}$, macaco gibão ${ }^{13}$ e Capricornis crispus $^{14}$, foi descrito o mesmo limite cranial, todavia na última espécie o plexo estende-se até $S_{5}$, enquanto que nas demais se encontra entre $\mathrm{L}_{3}-\mathrm{S}_{3}$.

Decorrente da confluência dos segmentos $\mathrm{L}_{3}-\mathrm{L}_{4}$ surge o nervo Genitofemoral, que foi evidenciado dividido em dois ramos muito delgados (Figura 2). Cursa um trajeto retilíneo, ventralmente na região abdominal, entre os músculos psoas maior e menor, dirigindo-se caudalmente até a região inguinal. Este supre os músculos oblíquo abdominal interno e cremáster, além de estruturas inguinais e genitais, como o escroto, o prepúcio e a glândula mamária ${ }^{9}$. Esta última área de inervação nos leva a inferir que este nervo regula, por meio de fibras

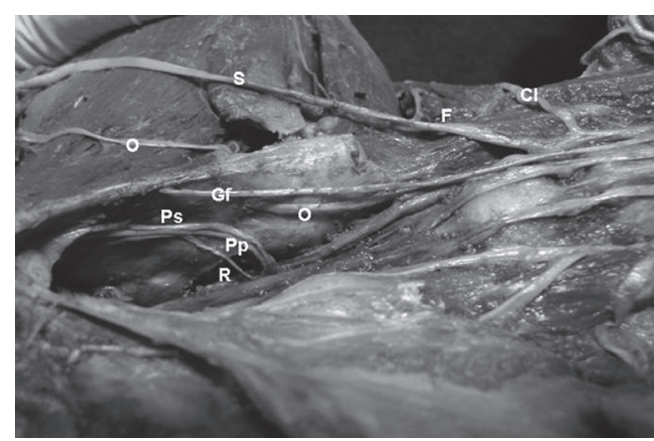

Figura 2 -Fotografia mostrando a disposição e trajeto dos nervos provenientes dos segmentos $\mathrm{L}_{3}-\mathrm{L}_{4}$ Genito-femoral (Gf), Obturatório $(\mathrm{O})$ e o Femoral (F) emitindo o nervo Safeno (S). Ainda ressaltamos os nervos Perineais Superficial (Ps) e Profundo (Pp), emitidos pelo nervo Pudendo, e Retal Caudal (R) provenientes dos segmentos $\mathrm{S}_{2-3}$ 
autônomas, o fluxo de leite durante a amamentação, visto que estabelece interconexões com o tronco simpático?. Porém, ressalta-se que para o estabelecimento de dados mais conclusivos sobre esta relação, seriam necessários estudos complementares com neurotraçadores como o cloreto de cobalto.

A partir da mesma confluência supracitada, $\mathrm{L}_{3}-\mathrm{L}_{4}$, surgem os outros dois nervos do plexo, que são o Obturatório e o Femoral (Figura 2), diferente do observado para espécies domésticas ${ }^{11}$ e em cães ${ }^{8}$, onde estes são descritos como formados de segmentos mais caudais. Também é importante salientar, que para estas espécies ambos os nervos são formados por três ou quatro segmentos, enquanto que em lobosmarinhos temos somente dois. Contudo, Rocha ${ }^{15}$ cita que o nervo femoral é formado por dois segmentos, assim como Schwarze e Schröder ${ }^{7}$ citam que o obturatório também se origina de forma semelhante, ambos os casos referem-se a cães. Porém, ambos relatam que os segmentos envolvidos são $\mathrm{L}_{4}-\mathrm{L}_{5}$ (Figura 2).

O obturatório é responsável por inervar a musculatura adutora do membro, suprindo o músculo obturador externo. Seu percurso é retilíneo até atingir o forame obturado, onde se dirige ao membro pélvico, transpondo este forame, projetando-se aos músculos pectíneo, grácilis e adutor, e promovendo a inervação dos mesmos.

O nervo Femoral foi observado sendo bastante delgado e cursando obliquamente a região ilíaca ventralmente, e suprindo os músculos lombares profundos, psoas maior e menor. Ao dirigir-se à região femoral, adentra e supre sua musculatura cranial, correspondente aos músculos reto femoral, vasto externo e vasto profundo ${ }^{5,6}$, que são os principais extensores da articulação femoro-tibio-patelar, sendo de extrema importância na locomoção do animal. Porém, antes de penetrar esta musculatura, emite o nervo Safeno ao nível do terço médio da região femoral cranial (Figura 2). Este nervo, relativamente calibroso, supre parte dos músculos sartório e grácilis que agem como adutores do membro, e a região cutânea sural ventrolateral, através da qual percorre um trajeto livre até a região digital ventral, inervando-a cutaneamente. Estas características refletem adaptações desta espécie, visto que em outros mamíferos, como carnívoros domésticos, observamos o nervo safeno pouco calibroso e direcionado a face medial do membro $^{16,11,9}$ (Figura 3).

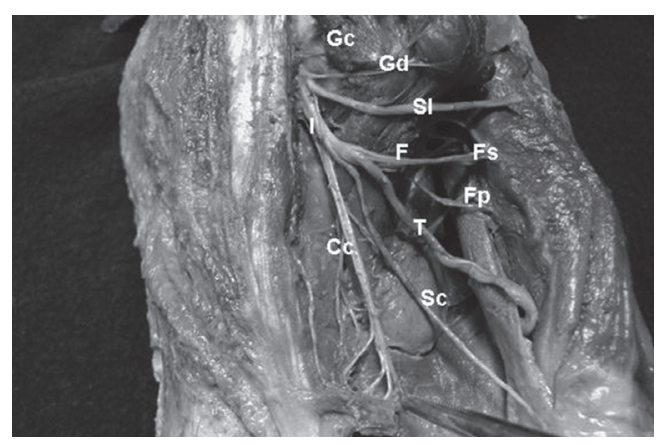

Figura 3 - Fotografia mostrando o plexo Isquiático, originado de $\mathrm{L}_{4-5}-\mathrm{S}_{1}$, emitindo: Glúteos Cranial (Gc) e Caudal (Gd), Cutâneo Femoral Caudal (Cc) e Isquiático (I). Este último emite os Cutâneos Surais Lateral (SI) e Caudal (Sc), Tibial (T) e Fibular Comum (F), que ramificase em Fibulares Superficial (Fs) e Profundo (Fp)

Os ramos remanescentes do PLS emergem de um grande tronco nervoso ${ }^{11}$, o Plexo Isquiático $(\mathrm{PI})^{7}$, composto pelos segmentos $\mathrm{L}_{4-5}-\mathrm{S}_{1}$. Este foi observado deixando a cavidade pélvica, percorrendo dorso-ventro-medialmente o osso coxal, e emitindo quase que imediatamente três ramos: Glúteos Cranial, Caudal e Cutâneo Femoral Caudal (Figura 3). Em seguida, continua-se como nervo Isquiático, cursando dorsalmente a região femoral logo abaixo dos músculos bíceps femoral e semimembranoso. Em carnívoros domésticos tem sua origem descrita de $\mathrm{L}_{6}$ $\mathrm{S}_{2}{ }^{7,9}$, contudo em cães, os primeiros descrevem a participação de $\mathrm{S}_{2}$ e $\mathrm{S}_{3}$, divergindo do encontrado em lobomarinho. Assim, como anteriormente descrito, os primeiros nervos emitidos são os Glúteos, que suprem à musculatura abdutora do membro. Porém, o nervo 
Glúteo Cranial inerva os músculos glúteos máximo, piriforme e parte do tensor da fáscia femoral, enquanto que o Caudal, supre o músculo glúteo mínimo e parte do semitendinoso. $\mathrm{O}$ músculo glúteo médio recebe ramos de ambos os nervos, semelhante ao relatado em cães. ${ }^{7,9}$

Responsável por inervar em parte os músculos semitendinoso e bíceps femoral, importantes abdutores do membro e flexores da articulação femoro-tibio-patelar, temos o nervo Cutâneo Femoral Caudal, que ainda emite ramos cutâneos que promovem a inervação da pele da região femoral caudal e perineal. Sua distribuição é semelhante à relatada para carnívoros domésticos. ${ }^{7,8}$ Este nervo foi observado sendo bastante calibroso e percorrendo um curso livre pela região sural dorsalmente.

O nervo Isquiático é a estrutura nervosa que apresenta maior espessura e encarrega-se de emitir ramos próprios para os músculos obturador interno, quadrado femoral e gêmeos superior e inferior, participando na inervação dos músculos bíceps femoral, semimembranoso e semitendinoso. Ao emergir da cavidade pélvica, percorre dorsal e distalmente a região femoral, onde logo após a articulação femoro-tibio-patelar emite os nervos Cutâneos Surais Lateral e Caudal, Fibular Comum e Tibial (Figura 3). Sua ramificação ocorre de modo semelhante ao descrito em outras espécies domésticas. ${ }^{9111,16}$

Observa-se o nervo Cutâneo Sural Lateral cursando um trajeto perpendicular à região sural, transpondo o músculo bíceps femoral. A partir deste ponto distribui-se subcutânea e lateralmente nesta região desde a articulação femoro-tibio-patelar até a társica, ocorrendo de forma semelhante a outras espécies domésticas. ${ }^{9,11,16}$ Evidenciouse, ainda, que este nervo emite ramos para o músculo sóleo. Dispondo-se dorsalmente à região sural, o nervo Cutâneo Sural Caudal inerva a pele desta mesma região e o tendão calcâneo comum, principal extensor da articulação társica.

Promovendo a inervação da musculatura e pele ventro-lateral sural e digital, observa-se o nervo Fibular Comum. Este, ao atingir proximal e dorsalmente a região sural ramifica-se em Fibular Superficial e Profundo. Tal ramificação não difere do proposto para outras espécies domésticas. ${ }^{8,9,17}$ Observou-se que ambos os ramos inervam os músculos flexores da articulação társica. O Fibular Superficial supre os músculos extensor digital longo, peroneu longo, peroneu breve e peroneu quinto. Já a musculatura mais profunda desta região, que abrange os músculos tibial anterior e extensor do hálux ${ }^{5,6}$, é suprida pelo nervo Fibular Profundo.

Sendo o ramo terminal de maior espessura emitido a partir do nervo Isquiático temos o Tibial, que posiciona-se dorsalmente à região sural dirigindo-se caudalmente e adentrando a musculatura dorso-medial do membro, promovendo a inervação desta. Esta musculatura, responsável pela extensão da articulação társica, é constituída pelos músculos gastrocnêmio, plantares, poplíteo, tibial posterior, flexor digital longo e flexor longo do hálux ${ }^{5,6}$. Seu trajeto é semelhante ao relatado por Rosa et al. ${ }^{18}$ para Didelphis sp. Distalmente à articulação társica, este emite os nervos plantares medial e lateral que suprem as regiões metatársica e digital. Assim como evidenciado por $\mathrm{Ghoshal}^{8}$ em cães, o nervo plantar medial emite, na região metatarsiana, os nervos digital plantar medial II e digitais plantares comuns I, II, III e IV. Ao nível da articulação metatarsofalangeana, cada nervo digital plantar comum subdividese em digitais plantares próprios axiais e abaxiais. Do nervo plantar lateral observamos a emissão dos nervos plantar lateral V e metatársicos plantares II, III e IV de modo similar a cães descrito pelo mesmo autor.

Emergindo dos segmentos $\mathrm{S}_{2-3}$ observamos os nervos Pudendo e Retal Caudal, onde o primeiro tem origem semelhante ao relatado por Schwarze e Schröder ${ }^{7}$ para porcos e por Ghoshal ${ }^{8}$ para cães. Ambos os nervos cursam trajetos paralelos entre si, obliquamente na cavidade pélvica direcionados do teto 
desta à sínfise púbica. Constatamos que o nervo Pudendo emite os nervos dorsal do pênis (clitóris) e perineais superficial e profundo (Figura 2). Atribui-se a nomenclatura de nervo dorsal do pênis (clitóris) a um ramo remanescente do Pudendo, que se dirigia a região peniana (vulvar). Não é possível tecer maiores considerações ao seu trajeto, em virtude do processo de evisceração relatado no item Material e Método. Este nervo supre em machos o pênis e prepúcio, e nas fêmeas o clitóris e vulva. O nervo perineal profundo supre a região ventral da musculatura estriada do períneo e os órgãos perineais, enquanto que o perineal superficial encarregase da pele do ânus, da vulva e da região perineal ventral. A ramificação do nervo Pudendo e o território de inervação de seus ramos foram averiguados semelhantes ao relatado para outras espécies domésticas ${ }^{17}$, 11, 9 . O nervo Retal Caudal (Figura 2) envia fibras sensoriais para o reto, o ânus e a pele perianal, bem como fibras motoras para a musculatura estriada perineal dorsal, incluindo o músculo levantador do ânus, assim como descrito para cães ${ }^{8}$.

Durante a realização da presente pesquisa evidenciou-se o tronco simpático promovendo interconexões, mediados por ramos comunicantes brancos, junto a todos os segmentos medulares lombares, fato importante visto que em outros mamíferos esta interconexão foi relatada, como em humanos, ocorrendo junto aos dois primeiros segmentos lombares ${ }^{19} \mathrm{e}$, em outras espécies domésticas, também somente junto aos segmentos lombares craniais, mais precisamente até o terceiro segmento lombar ${ }^{11,20}$. Isto ocorre devido os neurônios pré-ganglionares só existirem nestes segmentos, o que explica a existência de ramos comunicantes brancos apenas nas regiões torácica e lombar ${ }^{19}$. Esta evidência nos sugestiona que a íntima interação entre estas estruturas nervosas seja mais intensa nesta espécie que em outros mamíferos. Assim, o tronco simpático, considerado como o centro de respostas para estados de alerta e fuga, encontra-se promovendo uma maior interação com as estruturas que inervam o membro pélvico, o qual atua como principal propulsor na locomoção no meio aquático.

\section{Conclusão}

De posse dos resultados observados pode-se inferir que a sistematização da inervação lombar e sacral constitui-se de modo semelhante ao descrito para outras espécies. Porém, neste trabalho evidenciouse características próprias deste mamífero, que se decorrem de sua adaptação ao meio aquático. Deste modo conclui-se que a origem aparente da inervação lombar e sacral ocorre a partir dos segmentos medulares $\mathrm{L}_{1}$ a $\mathrm{S}_{3}$, onde observa-se como unissegmentares os nervos Ílio-hipogástrico, Ílio-inguinal e Cutâneo femoral lateral, respectivamente de $\mathrm{L}_{1}, \mathrm{~L}_{2}$ e $\mathrm{L}_{3}$. Os dois primeiros promovem suprimento nervoso da musculatura abdominal ventromedialmente, enquanto que o último o músculo psoas maior e pele da região femoral.

O PLS constatado sendo formado pelos nervos $\mathrm{L}_{3}$ a $\mathrm{S}_{1}$ e constituindo nervos plurissegmentares originados a partir de seus constituintes $\mathrm{L}_{3}-\mathrm{L}_{4}$, temos os nervos Genitofemoral, composto de dois ramos delgados e inervando o músculo oblíquo abdominal interno e a região genital, Obturatório, suprindo a musculatura adutora do membro, e o Femoral que inerva os músculos lombares profundos e a musculatura femoral cranial.

O Plexo Isquiático, oriundo da confluência dos segmentos $\mathrm{L}_{4-5}-\mathrm{S}_{1}$, foi evidenciado como um tronco nervoso emitindo os nervos Glúteos Cranial e Caudal, que supre a musculatura abdutora do membro, Cutâneo Femoral Caudal, suprindo o músculo semitendinoso, parte do bíceps femoral e pele perineal, e Isquiático. Este último emite os nervos Cutâneos Surais Lateral e Caudal, que inervam pele da região sural, Tibial, que supre a musculatura dorsomedial do membro, e Fibular Comum, que divide-se em Fibular Superficial e Profundo 
inervando a musculatura e pele ventro-lateral sural e digital.

Provenientes dos segmentos $S_{2-3}$ notase os nervos Pudendo, que emite os nervos dorsal do pênis (clitóris) e perineais superficial e profundo, e Retal Caudal que juntos suprem à musculatura peniana, perianal e vulvar.

No decorrer do estudo observou-se interconexões entre o tronco simpático e todos os nervos lombares.

\title{
The lumbar and sacral innervation of the Arctocephalus australis: sistematization and distribution
}

\begin{abstract}
In order to describe the innervation originated from ventral lumbar and sacral branches, a study was made through dissection of two specimens of south american fur seals (Arctocephalus australis), originated from CRAM-FURG, where they arrived deceased. The nervous structures that constitute the lumbar and sacral plexes are originated from ventral branches of spinal nerves which come from medullary segments $L_{1}$ to $S_{3}$. Thus, one can observe that the nerves originated form $\mathrm{L}_{1}$ to $\mathrm{L}_{3}$ are monosegmentary, being respectively iliohypogastric, ilioinguinal and lateral femoral cutaneous nerves. From the reunion of $\mathrm{L}_{3}$ and $\mathrm{L}_{4}$ segments arise genitofemoral, obturator and femoral nerves. From the confluence of segments $\mathrm{L}_{4}$ ${ }_{5}-\mathrm{S}_{1}$ arises a nervous trunk - the sciatic plexus, which gives the following nerves: cranial and caudal gluteal, caudal femoral cutaneous and sciatic. Sciatic nerve splits into lateral and caudal sural cutaneous, tibial, common peroneal. Pudendal nerve (which divides into dorsal nerve of the penis or clitoris, deep and superficial perineal) and caudal rectal are formed from the $\mathrm{S}_{2-3}$ segments. With these data, one can conclude that the lumbar and sacral innervation have similar origin to other mammal species, however its organization and distribution reflect the adaptative changes to this animals' habits, specially its locomotion in water.
\end{abstract}

\section{Referências}

1 ZERBINI, A.; SICILIANO, S.; PIZZORNO, J. L. A. Avaliação e ações prioritárias para a conservação da biodiversidade da zona costeira marinha: diagnóstico sobre mamíferos marinhos: anexo 2 - revisão das espécies. 1999. Disponível em: http://www.bdt.fat.org.br/workshop/ costa/mmarinho/anexo2 >. Acesso em: 4 nov. 2005.

2 SILVA, K.G.; ESTIMA, S. C.; MONTEIRO, D. S. Status de Conservação dos Pinípedes nas Áreas Protegidas do Litoral de Rio Grande do Sul - RS, nos anos de 2001 e 2002. SIMPÓSIO DE ÁREAS PROTEGIDAS CONSERVAÇÃO NO ÂMBITO DO CONE SUL, 2., 2003, Pelotas. Anais...

3 PINEDO, M. C. Mortalidade de Pontoporia blainvillei, Tursiops gephyreus, Otaria flavescens e Arctocephalus australis na costa do Rio Grande do Sul, Brasil. 19761983. In: REUNION DE TRABAJO DE EXPERTOS EN MAMIÍFEROS ACUÁTICOS DE AMERICA DEL SUR, 1 1986, Buenos Aires. Resumos... p.187-199, 1986.
Key words: Arctocephalus. Plexus. Lumbar. Sacral. Anatomy.
4 INTERNATIONAL COMMITTEE ON VETERINARY GROSS ANATOMICAL NOMENCLATURE. Nomina anatomica veterinaria. 5. ed. Ithaca: Dep. Vet. Anat., Cornell University, 2005. 190p.

5 MILLER, W. C. S. The myology of the Pinnipedia. Appendix to the report on seals. In: Turner, W. Report on the scientific results of the voyage of the H. M. S. Challenger during the years 1873-76. v.1, pt. 4, p. 139234, 1887.

6 HOWELL, A. B. Contribution to the comparative anatomy of the eared and earless seals (Genera Zalophus and Phoca). Proceedings U. S. National Museum, v. 73, n. 2736, art. 15, 1929.

7 SCHWARZE, E.; SCHRÖDER, L. Compendio de anatomia veterinaria. Zaragoza: Acribia, 1970, v.4. 208 p.

8 GHOSHAL, N. G. Nervos espinhais - sistema nervoso do carnívoro. In: SISSON, S. Sisson Grossman: anatomia dos animais domésticos. 5. ed. Rio de Janeiro: Guanabara-Koogan, 1986. p. 1595- 1617. 
9 KÖNIG, H. E.; LIEBICH, H. J. Anatomia dos animais domésticos. Porto Alegre: Artmed, 2002, v. 2. 399 p.

10 BARROS, R. A. C.; PRADA, I. L. S.; SILVA, Z; RIBEIRO, A. R.; SILVA, D. C. O. Constituição do plexo lombar do macaco Cebus apella. Braz J Vet Res Anim Sci, v. 40, n. 5, p. 373-381, 2003.

11 DYCE, K. M.; SACK, W. O.; WENSING, C. J. G Tratado de anatomia veterinária. 2. ed. Rio de Janeiro: Guanabara Koogan, 1997. 663 p.

12 TEIXEIRA, D. G.; OLIVEIRA, M.F.; MIGLINO, M. A.; PASSIPIERI, M; MOURA, C. E. B.; COSTA, W. P.; BENEDICTO, H.G.; PEREIRA, F.T.V.; AMBROSIO, C. E. Origem do Plexo Lombossacral do Cervo do pantanal. Resumos do IVCongreso de Anatomía del Cono Sur XX Congresso Brasileiro de Anatomia, XXIII Congreso Chileno de Anatomía, XXXIX Congreso Argentino de Anatomía, I Simpósio sobre Ensino de Anatomia. International Journal of Morphology, v. 21, n. 1 , p. 49-92, 2003.

13 OLIVEIRA, M. F.; MIGLINO, M. A.; PASSIPIERI, M.; TEIXEIRA, D. G.; MOURA, C. E. B.; COSTA, W. P.; BENEDICTO, H. G.; PEREIRA, F. T. V.; AMBROSIO, C. E.; ASSIS NETO, A. C. Derivação do plexo lombossacral em macaco gibão (Hylobates sp.) Resumos do IVCongreso de Anatomía del Cono Sur XX Congresso Brasileiro de Anatomia, XXIII Congreso Chileno de Anatomía, XXXIX Congreso Argentino de Anatomía, I Simpósio sobre Ensino de Anatomia. International Journal of Morphology, v. 21, n. 1, p. 49-92, 2003.
14 ATOJI, Y.; SUZUKI, Y.; SUGIMURA, M. The lumbosacral plexus of the Japanese serows, Capricornis crispus. Anat Anz, v. 164, n. 3, p. 213-217, 1987.

15 ROCHA, L. M. S. Estudo anátomo-anestesiológico do segmento lombar (L1 a L6) em cães. 2003. $81 \mathrm{f}$. Dissertação (Mestrado) - Faculdade de Medicina Veterinária e Zootecnia, Universidade de São Paulo, São Paulo, 2003.

16 MILLER, M. E.; CHRISTENSEN, G. C.; EVANS, H. E. Anatomy of the dog. Philadelphia: Saunders Company, 1964. 941 p.

17 POPESKO, P. Atlas de anatomia topográfica dos animais domésticos. São Paulo: Manole, 1985, v. 3.616 p.

18 ROSA, R. A. ROQUETTO, M. A.; SANTOS, A.M.A.C.; MIGLINO, M. A.; AMBROSIO, C. E.; CARVALHO, A. F.; MARTINS, J. F. P.; MANÇANARES, C. A. F.; CASALS, J.; BELLATINE, T.; VALVERDE, C. W. Análise macroscópica da inervação pélvica do Didelphis sp. In: REUNIÃO DE INTEGRAÇÃO DA MORFOLOGIA PAN-AMERICANA, 2004, Foz do Iguaçu. Resumo... Foz do Iguaçu, 2004, v.1, p. 347.

19 MACHADO, A. B. M. Neuroanatomia funcional. 2. ed. São Paulo: Atheneu, 2000. 363 p.

20 INTELIZANO, T. R.; SANTOS, P. R.; FUTEMA, F.; OTSUKI, D. O.; ALMEIDA, T. A.Técnicas de anestesia local. In: FANTONI, D. T.; CORTOPASSI, S. R. G. Anestesia em cães e gatos. São Paulo: Roca, 2002. p. 206-208. 